\title{
Effectiveness of behavioral therapy in obese children in outpatient clinic
}

\author{
Piotr Gibała ${ }^{1}$, Anna Springwald ${ }^{2}$, Patrycja Różana ${ }^{1}$, Ewa Małecka-Tendera², Paweł Matusik ${ }^{2}$ \\ ${ }^{1}$ Scientific Society of Medical Students, Medical University of Silesia, Katowice, Poland \\ 2Department of Pediatrics and Pediatric Endocrinology, School of Medicine in Katowice, Medical University of Silesia, \\ Katowice, Poland
}

\begin{abstract}
Objective: The aim of the study was to evaluate the effectiveness of behavioral therapy in childhood obesity in metabolic outpatient clinic.
\end{abstract}

Material and methods: Records of the 587 (289 boys) obese children in the age of $10.73 \pm 3.57$ were retrospectively analyzed (2005-2016). The therapy included lifestyle modification (increased physical activity, and support from the dietician and psychologist). Anthropometrical assessment was based on BMI $z$-score index.

Results: Initial BMI $z$-score was higher in boys (3.29 SD vs. $2.66 \mathrm{SD}, p<0.00001)$. At follow-up visit for an average of 3 months, with a $66.8 \%$ of the children reported, an improvement was observed in $70 \%$ of them, and greater weight loss was found in boys ( $\triangle \mathrm{BMI} Z$-score: $0.28 \mathrm{SD}$ vs. $-0.15 \mathrm{SD}$ ). Improvement of the nutritional status ( $\triangle \mathrm{BMI} Z$-score) correlated with the age of children and the initial weight (vs. age: $r=0.233, p<0.01$; vs. BMI $Z$-score: $r=-0.610, p<0.00001)$. Further follow-up showed a reduction in the number of children continuing the treatment (at the $3^{\text {rd }}$ visit: $28.3 \%$; at the $4^{\text {th }}$ visit: $19.1 \%$; at the $5^{\text {th }}$ visit or more: $12.7 \%$ ). In children, who remained under control of the outpatient clinic, a reduction in BMI $z$-score $(p<0.00001)$ was observed from the $3^{\text {rd }}$ visit.

Conclusions: Behavioral therapy on the outpatient clinic level is effective, but its effectiveness is pointedly reduced by the high number of children and their parents who avoid the treatment or refuse to continue this model of therapy. The essential challenge is to keep the motivation of both parents and children.

Key words: childhood obesity, behavioral treatment, BMI, outpatient clinic.

\section{Introduction}

Obesity is the most common chronic metabolic disorder among children and adolescents in well developed countries. According to the World Health Organization (WHO), it is the most widespread medical problem in childhood. Since 1985, in accordance with WHO, obesity is classified as a disease [1]. It is difficult to estimate the scale of the problem because number of children, who suffer from obesity has increased significantly in recent twenty years.

According to the study from 2013, overweight concern $14 \%$ of children in the World. Almost $20 \%$ of European children struggle with overweight and obesity [2]. In Polish children population, obesity was diagnosed in
$3.7 \%$ girls and $3.6 \%$ boys $[3,4]$, and this is the reason why we should pay special attention to these children in clinical practice. In consequence, they are likely to stay obese in future.

The obesity epidemic is a serious and growing problem for public health systems worldwide [5-7], affecting all age groups including very young children [8]. The main and the most important problem of obesity are the short- and long-term consequences. Obesity can lead to numerous comorbidities such as diabetes mellitus type 2, hypertension, hyperlipidemia, or metabolic syndrome $[8,9]$. These progressive disorders lead to decline life expectancy. Regardless of multiple organic diseases, obesity often conduce to psychological distresses because is inevitably accompanied by discrimination and stigmatization 
$[10,11]$. It leads to emotional deprivation and social-life impairment. Prevention and early treatment of obesity are crucial to restrain the epidemic, making children one of the main target groups for public health interventions.

Outpatient clinic treatment are the crucial part of public health interventions because they have frequent personal contacts with the patients and their families, and can play an important role in the prevention, early diagnosis, and treatment of childhood obesity.

The problem is broad-based. We can observe noticeable increase in prevalence of obesity. It is caused by a lot of various factors. Mainly due to changes in the environment and behavior relating to diet and activity. Biological and socio-economic factors are important $[12,13]$. Nowadays, it is little to know about the impact of genetic causes on obesity developing. Increasingly popular epigenetics may play a significant role in evolution of this disorder [14]. However, the precise etiology is still not known.

The most difficult matter is the treatment. What we can do now, in primary care, is behavioral therapy $[9,15]$. Behavioral treatment is an approach used to help individuals to develop a set of skills to improve or even normalize their weight. It is more than helping children to decide what to change; it is helping them to recognize how to change. The behavior change process is facilitated through the use of self-monitoring, goal setting, and problem solving [16].

We still know few about the effectiveness of this treatment, and the number of articles considering this method is scarce [17-19]. More studies are needed to asses this kind of therapy in obese children. Additionally, this therapy is regarded to be not effective enough, and bariatric surgery is now more often considered in pediatric population. However, it seems to be the last-choice solution and applied only in the morbidly obese adolescents. According to these questions, we decided to evaluate the effectiveness of behavioral therapy as a non-invasive way of treatment in outpatient clinic dedicated to the childhood obesity therapy within the third level of the Polish health care system.

\section{Material and methods}

Study group (SG) comprised of 589 (289 boys, 298 girls) obese children. Mean age was $10.73 \pm 3.57$. We did

Table 1. General characteristics of subgroups boys and girls

\begin{tabular}{|l|c|c|c|}
\hline & Boys & Girls & $p$ \\
\hline Age (years) & $11.02 \pm 3.71$ & $10.82 \pm 3.94$ & 0.47 \\
\hline Weight (kg) & $67.96 \pm 26.95$ & $61.09 \pm 25.75$ & 0.001 \\
\hline BMI (kg/m²) & $28.57 \pm 5.54$ & $27.26 \pm 6.09$ & 0.006 \\
\hline BMI z-score & $3.29 \pm 1.23$ & $2.66 \pm 1.03$ & 0.000001 \\
\hline
\end{tabular}

not observe significant differences of age between subgroups of boys and girls, respectively (11.02 years SD 3.71 vs. 10.82 years SD 3.94). More than $70 \%$ of children lived in cities, with over 100,000 of citizens. The retrospective case-control study was conducted in the Metabolic Outpatient Clinic in Children's Hospital in Katowice between 2014 and 2016, with data from years 2005 to 2016. Exclusion criteria comprised secondary causes of obesity such as chronic intake of certain drugs, endocrinopathies, genetically determined disorders, and other chronic diseases. As far as the therapy is concerned, only behavioral treatment was introduced. The therapy included lifestyle modification, and the children were encouraged to increased physical activity and change eating patterns. Moreover, they were supported by the dietician and psychologist. Obesity was determined according to the WHO growth references for children from 2007. We used BMI $z$-score for age and sex. Children with $z$-score $+2 \mathrm{SD}$ or more were classified as obese. Patients have visited outpatient clinic every three months. Each time, anthropometric measurements such as height, weight, and body mass index (BMI) were performed. Weight was measured in the standing position, with an accuracy of $100 \mathrm{~g}$. Height was obtained in the standing position with a fixed stadiometer, with an accuracy of $1 \mathrm{~cm}$. Body mass index was calculated using the standard formula (kilograms per meter squared). BMI $z$-scores were derived using WHO AnthroPlus, version 1.0.4 (based on the World Health Organization growth references). Comparative analysis of the groups for the variables with normal distribution was performed using the Shapiro-Wilk test. Analysis for qualitative variables was carried out using a chi-square test. Analysis for quantitative variables with normal distribution was carried out using $T$-test. Analysis for quantitative variables without normal distribution was carried out using Mann-Whitney $U$ test. Correlation coefficient was signified by Pearson correlation. All results were analyzed in the Statistica $^{\mathrm{Tm}} 12 \mathrm{PL}$ software. The criterion of statistical significance was set as $p<0.05$.

\section{Results}

General characteristics of study group are presented in Table 1. Initial BMI $z$-score was higher in boys ( $p=$ $0.00001)$. In subgroup of boys, we noticed higher BMI than in subgroup of girls, respectively $(p=0.006)$. Greater weight loss and reduction of BMI $z$-score was found in subgroup of boys than in girls, respectively $(-1.37 \mathrm{~kg} \mathrm{SD}$ 2.85 vs. $-0.45 \mathrm{~kg} \mathrm{SD} 4.89)$; ( $\Delta \mathrm{BMI} z$-score -0.28 ; SD 0.38 vs. -0.18 ; SD 0.36). Improvement of the nutritional status ( $\triangle \mathrm{BMI} Z$-score) correlated with the age of children and the initial BMI $z$-score (vs. age of children $r=0.154, p=$ 0.003 [Figure 1]; vs. BMI z-score: $\mathrm{r}=-0.371, p<0.00001$ 
Pearson correlation between Age of children and delta BMI Z-score measured on $2^{\text {nd }}$ visit. $r=0.154, p=0.003$

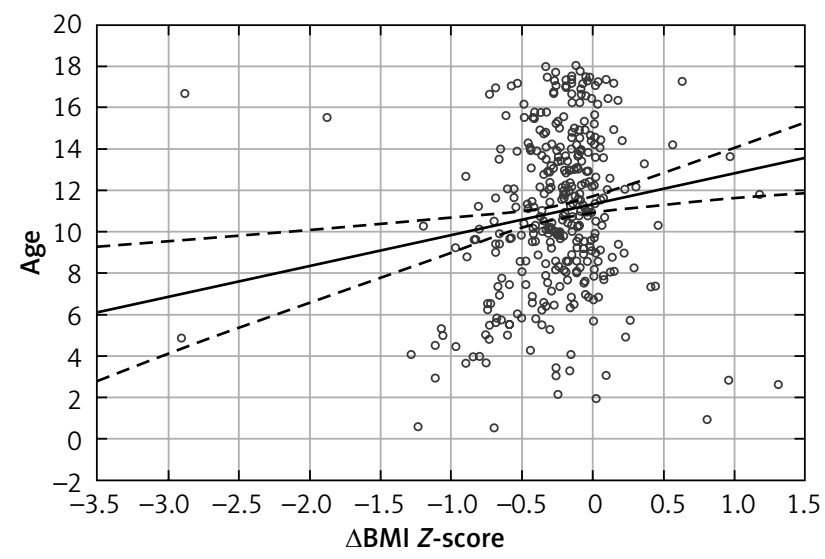

Figure 1. Correlation between age of children and delta BMI $z$-score measured on $2^{\text {nd }}$ visit

[Figure 2]). We did not observe statistical correlation between BMI $z$-score and birth weight $(p>0.05)$.

At follow-up visit for an average of 3 months, with a $66.8 \%$ of the children reported, an improvement was observed in $70 \%$ of them. Further follow-up showed a reduction in the number of children continuing treatment: at the $3^{\text {rd }}$ visit: $n=172(29.8 \%)$; at the $4^{\text {th }}$ visit: $n=110$ $(19.1 \%)$; at the $5^{\text {th }}$ visit or more: $n=70(12.3 \%)$ (Figure 3$)$. However, a constant decrease in BMI $Z$-score was observed until the $5^{\text {th }}$ visit (Figure 4 ).

In children, who remained under control of the outpatient clinic, a reduction in BMI $z$-score $(p<0.00001)$ was observed from the $3^{\text {rd }}$ visit.

No statistically significant differences were found between the age of children, average BMI, and BMI z-score of children, who came only on first visit and those who were continuing the treatment.

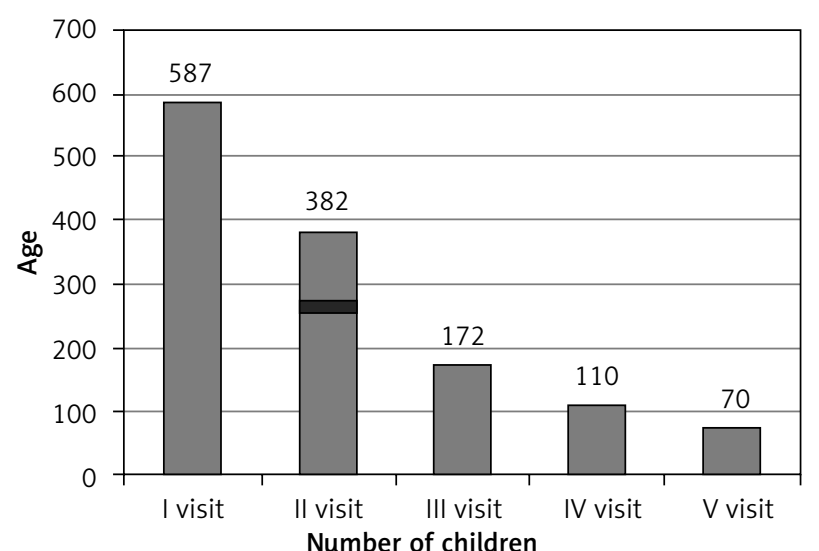

$70 \%$ of children who had improvement of BMI Z-score on II visit $(n=267)$

Figure 3. Number of children treated in the Metabolic Outpatient Clinic
Pearson correlation between BMI Z-score and delta BMI Z-score measured on $2^{\text {nd }}$ visit. $r=-0.371, p<0.00001$

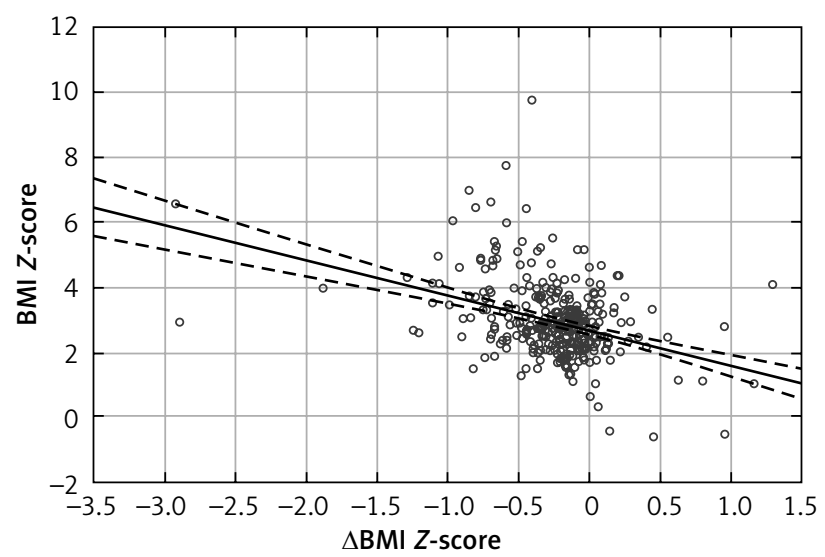

Figure 2. Correlation between BMI z-score and delta BMI $z$-score measured on $2^{\text {nd }}$ visit

\section{Discussion}

Our study confirmed that the behavioral therapy on the outpatient clinic level can be effective in the obese children, as we found a significant improvement of BMI $z$-score at follow-up visits. The participants in our study had a mean reduction in BMI $z$-score of 0.43 at third visit (i.e., six months observation). In a study by Videira-Silva et al., a reduction in BMI $z$-score of only $0.05 \mathrm{SD}$ were reported, after similar period of intervention. It should be noted that children who took part in this study attended pediatric and nutrition consultations. This investigation compared two groups: first group consisted of children with traditional pediatric consultation, and second involved patients with physical activity (PA) consultation. In the second group, BMI $z$-score significantly decline $(-0.05$ vs. -0.12$)$ [20]. In our research, we observed that

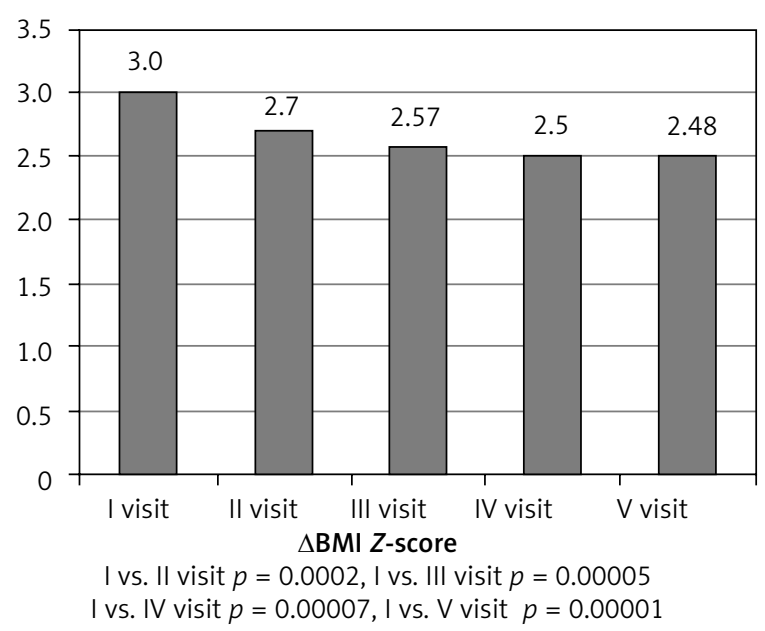

Figure 4. Average delta BMI $z$-score on particular visit and statistical differences between them 
from the first until the last visit in outpatient clinic, the reduction of BMI $z$-score was $0.52 \mathrm{SD}$. Kolsgaard et al. reported reduction in BMI z-score after one year of lifestyle intervention by 0.13 SD [21]. Study conducted by Bocca et al. reported that the reduction of BMI $z$-score amounts to 0.28 during 36-month follow-up [22]. Another work compared the effects of a multidisciplinary intervention program, with a usual-care program during 12 months of therapy, showing BMI $z$-score reduction as -0.6 vs. -0.3 $\mathrm{SD}$ [23]. The treatment has to be comprehensive and involve multifarious activities to be successful.

Stunkard et al. emphasized that behavioral therapy is not simply the third component of the treatment, apart from diet and exercises, but represents an expertise-driven approach to improving diet and physical activity using behavioral principles [17]. Similar results were obtained by Rajjo et al. [18], where the effectiveness of combined interventions consisting of physical activity, dietary modification, behavioral therapy, and education was demonstrated. It resulted not only in BMI reduction but also systolic and diastolic blood pressure, and triglycerides improved results. According to Mazur et al., primary health care should have a critical role in obesity management, but still it is not performed effectively as a result of insufficient competence. The main problem is not elaboration of guidelines but creating support systems for implementation medical standards in primary care [19]. For now, the most effective treatment can be performed in metabolic outpatient clinic, but it is not always possible and sufficient. The access to support overweight and obese children should be simpler.

The other problem is the attitude of general practitioners regarding obesity and their awareness of the $\mathrm{Na}$ tional Health and Medical Research Council (NHMRC) clinical practice guidelines. According to the study of Sivertsen et al., only few use these guidelines and the body mass index charts to correctly diagnose childhood obesity [24]. Among the authors in Dettori et al., almost all general practitioners agreed that child overweight and obesity was a medical problem, but only half of them have reported changing their practice [25]. Wilfley et al. described the conclusions from the conference concerning the improvement of prevention of childhood obesity in USA. The participants came to the common conclusion that to achieve a clinically significant BMI reduction, behavioral therapy, health care of good quality, and taking advantage of proofbased protocols is essential [26].

It should be emphasized that behavioral therapy is related not only to the children but also to their parents. Spence [27] in his study focused on behavioral therapy as well as psychoeducation of parents of overweight or obese children. His analysis included body mass of parents, socioeconomic status, and health state of the family. Schools engage in the fight against increasing epidemic of obesity as well. They try to encourage children to strongly involve in physical activity through multiple kind of sport. Farmer [28] conducted an interesting investigation in New Zealand. In several schools, physical education lessons were modified to riskier and posing bigger challenge for students. In general, schools liked this idea of increasing physical activity, and plenty of benefits were reported. Unfortunately, it did not reflect in statistically significant rise of physical activity or BMI reduction in children. We observed higher initial BMI z-score among group of boys. Higher prevalence of morbid obesity in boys was also confirmed among Chinese children in a work by Zhang et al. [29]. Whitlock et al. reported in their study that the overall age-adjusted prevalence of overweight was significantly greater in males than in females (5-17 years old) [30]. The most probable reason for this phenomenon seems to be the fact that girls (in adolescence period) more often pay attention to their appearance than boys. They are also more aware of their body, as slimness determine their attractiveness. We can also suspect that boys spend more time surfing on the internet, playing computer games, and watching TV.

As we found in our study, children's age plays a significant role in the treatment. The older the child, the easier to lose weight and follow the specialist's advices as well as abide essential rules. It is not surprising that it results from increasing awareness of the maturing child. What is more, through media, teenagers are also introduced to a number of ways to lose weight and achieve this thin perfection [31]. According to Chung [34], older children more precisely perceived weight status, because their perception of obesity is accurate.

Moreover, in our investigation, we observed greater weight loss in boys than in girls. Similar results were obtained by Czerwonogrodzka-Senczyna et al., although a higher reduction of the analyzed indicators was observed in the group of boys [32]. We presume that boys in school age are more eager to spend time actively, for example playing football with their friends, while majority of girls do not undertake the recommended level of daily physical activity [33]. This is also associated with higher initial BMI $z$-score among boys, which was confirmed in our study. The more obese children, the greater weight loss was observed. They may be more motivated to achieve a goal and feel stronger cultural pressure to be thinner. Chung et al. also confirmed that obese children were engaged in more weight loss behaviors than children with lower weight [34].

Our study showed that the apparent improvement of the BMI was seen only from the third visit. It may result from the fact that most of patients visited metabolic outpatient clinic for the second time just to see the results of their biochemical tests. Their motivation was too low to continue the therapy and change their lifestyle. Children who 
went to their third visit were persuaded enough to keep the strict rules, so as to achieve the goal and the ideal body mass. It is difficult to assess who is going to continue the therapy and estimate whose prognosis are better at the first visit. Analysis the number of children continuing the treatment showed a gradual reduction of patients at further follow-up appointments. It is not surprising that the amount of reasons for this negative phenomenon is countless. While children lose weight and observe positive effects of the therapy, they often see no reason to continue the therapy and be under control of the doctor. Conversely, lack of spectacular effects significantly weakens the motivation for longer therapy [32]. Similar phenomenon was observed in the trial conducted by Smith et al., in which more than half of participants adhered to the dietary principles and reduced over time [35]. On the other hand, study of Sousa et al. revealed that the time since the first visit does not significantly influence treatment adherence [36]. Thus, it is no wonder that patients' non-adherence to medical treatment remains a persistent problem [37-39]. The generalized initial enthusiasm for the use of guidelines has steadily declined during therapy. This is a disconcerting appearance, which encourage us to do even more in this matter. The challenge of our times is to keep the motivation of both parents and children [40]. Behavioral changes in eating, physical activity, and lifestyle should be not a temporary modification, but a constant alteration of the way of living.

\section{Disclosure}

The authors report no conflict of interest.

\section{References}

1. Health implications of obesity. National Institutes of Health Consensus Development Conference Statement. Ann Intern Med 1985; 103: 147-151.

2. Kuźbicka K, Rachoń D. Bad eating habits as the main cause of obesity among children. Pediatr Endocrinol Diabetes Metab 2013; 19: 106-110.

3. Januszek-Trzciąkowska A, Małecka-Tendera E, Klimek K, Matusik P. Obesity risk factors in a representative group of Polish prepubertal children. Arch Med Sci 2014; 10: 880-888.

4. Malecka-Tendera E, Klimek K, Matusik P, et al. Obesity and overweight prevalence in Polish 7- to 9-year-old children. Obes Res 2005; 13: 964-968.

5. James PT, Leach R, Kalamara E. The worldwide obesity epidemic. Obes Res 2001; 9 Suppl 4: 228-233.

6. Wang Y, Beydoun MA. The obesity epidemic in the United States-gender, age, socioeconomic, racial/ethnic, and geographic characteristics: a systematic review and meta-regression analysis. Epidemiol Rev 2007; 29: 6-28.

7. Lobstein T, Frelut ML. Prevalence of overweight among children in Europe. Obes Rev 2003; 4: 195-200.

8. Matusik P, Malecka-Tendera E. Overweight prevention strategies in preschool children. Int J Pediatr Obes 2011; 6 Suppl 2: 2-5.

9. Chen EY, Olino TM, Conklin CJ, et al.; Genetic and Neural Biomarkers of Obesity study group. Genetic and neural predictors of behavioral weight loss treatment: a preliminary study. Obesity (Silver Spring) 2017; 25: 66-75.

10. Sikorski C, Luppa M, Kaiser M, et al. The stigma of obesity in the general public and its implications for public health - a systematic review. BMC Public Health 2011; 11: 661.

11. Latner JD, Stunkard AJ. Getting worse: the stigmatization of obese children. Obes Res 2003; 11: 452-456.

12. Mazur A, Klimek K, Telega G, et al. Risk factors for obesity development in school children from south-eastern Poland. Ann Angric Environ Med 2008; 15: 281-285.

13. Wojdon-Machała H. Overweight in schoolchildren and some environmental factors. Roczniki PZH 1984; 35: 145-149.

14. Herrera BM, Keildson S, Lindrgen CM. Genetics and epigenetics of obesity 2011. Maturitas 2011; 69: 41-49.

15. Styne DS, Arslanian SA, Connor EL. Pediatric Obesity - Assessment, Treatment and Prevention: An Endocrine Society Clinical Practice Guideline. J Clin Endocrinol Metab 2017; 102: 709-757.

16. Foster GD, Makris AP, Bailer BA. Behavioral treatment of obesity. Am J Clin Nutr 2005; 82: 230-235.

17. Stunkard A. Diet, exercise and behavior therapy: a cautionary tale. Obes Res 1996; 4: 293-294.

18. Rajjo T, Mohammed K, Alsawas M, et al. Treatment of Pediatric Obesity: An Umbrella Systematic Review. J Clin Endocrinol Metab 2017; 102: 763-775.

19. Mazur A, Matusik P, Revert K, et al. Childhood obesity: knowledge, attitudes, and practices of European pediatric care providers. Pediatrics 2013; 132: e100-108.

20. Videira-Silva $A$, Fonseca $H$. The effect of a physical activity consultation on body mass index z-score of overweight adolescents: results from a pediatric outpatient obesity clinic. Eur J Pediatr 2017; 176: 655-660.

21. Kolsgaard ML, Joner G, Brunborg C, et al. Reduction in BMI z-score and improvement in cardiometabolic risk factors in obese children and adolescents. BMC Pediatr 2011; 11: 47.

22. Bocca G, Corpeleijn E, van den Heuvel ER, et al. Three-year follow-up of 3-year-old to 5-year-old children after participation in a multidisciplinary or a usual-care obesity treatment program. Clin Nutr 2014; 33: 1095-1100.

23. Bocca G, Corpeleijn E, Stolk RP, Sauer PJ. Results of a multidisciplinary treatment program in 3-year-old to 5-year-old overweight or obese children: a randomized controlled clinical trial. Arch Pediatr Adolesc Med 2012; 166: 1109-1115.

24. Sivertsen LM, Woolfenden SR, Woodhead HJ, Lewis DJ. Diagnosis and management of childhood obesity: a survey of general practitioners in South West Sydney. J Paediatr Child Health 2008; 44: 622-629.

25. Dettori H, Elliott H, Horn J, Leong G. Barriers to the management of obesity in children - a cross sectional survey of Gps. Aust Fam Physician 2009; 38: 460-464.

26. Wilfley DE, Staiano AE, Altman $M$, et al. Improving access and systems of care for evidence-based childhood obesity treatment: Conference key findings and next steps. Obesity (Silver Spring) 2017; 25: 16-29.

27. Spence ND, Newton AS, Keaschuk RA, et al. Predictors of Shortand Long-Term Attrition From the Parents as Agents of Change Randomized Controlled Trial for Managing Pediatric Obesity. J Pediatr Health Care 2017; 31: 293-301.

28. Farmer VL, Williams SM, Mann J, et al. The effect of increasing risk and challenge in the school playground on physical activity and weight in children: a cluster randomised controlled trial. Int J Obes 2017; 41: 793-800.

29. Zhang YX, Chu ZH, Li SY, et al. Trends in the Prevalence of Morbid Obesity among Children and Adolescents in Shandong, China, 1995-2014. J Trop Pediatr 2018; 64: 60-66 
30. Whitlock EP, Williams SB, Gold R, et al. Screening and Interventions for Childhood Overweight. Agency for Healthcare Research and Quality, Rockville 2005.

31. Dieting in adolescence. Paediatr Child Health 2004; 9: 487-491.

32. Czerwonogrodzka-Senczyna A, Majcher A, Sapiecha-Neffe D, et al. Analysis of the effectiveness of dietary counseling for children and adolescents with simple obesity, VI Congress of Polish Society for Paediatric Endocrinology and Diabetology. Poster (P80). Pediatr Endocrinol 2015; 14 Suppl 1: 14.

33. Staurowsky EJ, DeSousa MJ, Ducher G, et al. Her Life Depends On It II: Sport, Physical Activity, and the Health and Well-Being of American Girls and Women. Women's Sports Foundation, East Meadow 2009.

34. Chung AE, Perrin EM, Skinner AC. Accuracy of child and adolescent weight perceptions and their relationships to dieting and exercise behaviors: a NHANES study. Acad Pediatr 2013; 13: 371-378.

35. Smith KL, Kerr DA, Howie EK, Straker LM. Do Overweight Adolescents Adhere to Dietary Intervention Messages? Twelve-Month Detailed Dietary Outcomes from Curtin University's Activity, Food and Attitudes Program. Nutrients 2015; 7: 4363-4382.

36. Sousa PM, Gaspar P, Fonseca H, Gaspar F. Association between treatment adherence and quality of life among overweight adolescents. Cad Saude Publica 2017; 33: e00171815.

37. Dulmen S, Sluijs E, Dijk L, et al. Patient adherence to medical treatment: a review of reviews. BMC Health Serv Res 2007; 7: 13.

38. Haynes R, Yao X, Degani A, et al. Interventions to enhance medication adherence. Cochrane Database Syst Rev 2005; 1-96.

39. Roter DL, Hall JA, Merisca R, et al. Effectiveness of interventions to improve patient compliance: a meta-analysis. Med Care 1998; 36: 1138-1161.

40. National Institutes of Health. The practical guide: identification, evaluation, and treatment for overweight and obesity in adults. National Institutes of Health, Bethesda 2000. 